\title{
Cardioprotective Effect of Quercetin in 5/6-Nephrectomized Rats: Focus on Myocardial fibrosis and Oxidative Stress
}
Authors
Tri Yuliani $^{1,2^{*}}$, Melva Louisa ${ }^{2}$, Wawaimuli Arozal ${ }^{2}$, Vivian Soetikno ${ }^{2}$, Nafrialdi ${ }^{2}$, Indah D Dewijanti $^{3}$
Afiliation
${ }^{1}$ Master Program in Biomedical Science, Faculty of Medicine, University of Indonesia, Jakarta, Indonesia
${ }^{2}$ Departement of Pharmacology, Faculty of Medicine, University of Indonesia, Jakarta, Indonesia
${ }^{3}$ Research Center for Chemistry, Indonesian Institute of Sciences (LIPI), Serpong, Indonesia

\section{Keyword \\ O Quercetin \\ O Uremia, \\ O Heart \\ $\rightarrow$ Nephrectomy \\ - Captopril}

Received 7 September 2015

Revised 26 July 2016

Accepted 3 November 2017

*Corresponding author Tri Yuliani

Kawasan Puspiptek, Serpong, Kota Tangerang Selatan, Banten 15314, Indonesia anik_baik@yahoo.com

\section{ABSTRACT}

Uremic cardiomyopathy is the leading cause of death in patients with chronic kidney disease. Fluid overload and oxidative stress play important roles in its pathogenesis. This study aims to determine the effect of quercetin on uremic cardiomyopathy in 5/6-nephrectomized rats. To our knowledge, its cardioprotective effect on uremic cardiomyopathy induced in rats by $5 / 6$ nephrectomy has not been investigated yet. Uremia was induced surgically in male Sprague-Dawley rats via 5/6 nephrectomy. Quercetin was administered per orally at a dose of $100 \mathrm{mg} / \mathrm{kg} / \mathrm{day}$ for 8 weeks prior to sacrifice. Meanwhile, captopril was administered at a dose of 10 $\mathrm{mg} / \mathrm{kg} /$ day. Lipid peroxidation was assessed using TBARS reaction, while GPX activity was determined to explore the endogen antioxidant mechanism. Myocardial fibrosis was analyzed using Massons' Trichrome staining and the level of NT-proBNP in plasma was measured as a marker of cardiac dysfunction. Nephrectomy $5 / 6$ had no effects on plasma NT- proBNP levels, cardiac and plasma MDA levels, but induced mild myocardial fibrosis and significant increase in cardiac GPX activity in comparison with normal rat $(p<0.05)$. However, administration of quercetin or captopril did not ameleriote those mild myocardial fibrosis and increased GPX activity. Uremic cardiomyopathy induced by $5 / 6$ nephrectomy demonstrated mild myocardial fibrosis but preservation of cardiac function demonstrated by NT-proBNP levels. Increased of GPX activity in the nephrectomized-rats compared to the control rats $(p<0.05)$ suggests induction of antioxidant defense mechanisms that might not be exhausted yet. This condition highlighted a compensatory phase which was unchanged following chronic administration of either quercetin or captopril.

\section{INTRODUCTION}

The prevalence of chronic kidney disease (CKD) is estimated to be $8-16 \%$ worldwide, and $0.2 \%$ of the patients are found in Indonesia (Jha et al. 2013; Kemenkes $\mathrm{RI}, 2013$ ). It is worth nothing, that this number keeps increasing in both developed and 
developing countries (Small et al. 2012). Mortality of CKD is caused by cardiovascular complication suffered by $50 \%$ of patient rather than progression to end stage renal disease (ESRD) (Smith et al. 2009; Xie et al. 2015). Sudden death counts for $60 \%$ of the cardiovascular mortality that is mostly because of arrythmia caused by myocardial fibrosis (Glassock et al. 2009). Xie et al. (2015) found myocardial fibrosis due to uremic cardiomyopathy in almost 95\% of CKD patients.

Uremic cardiomyopathy was caused by pressure overload, volume overload, and uremic toxin itself (Lopez et al. 2008). Uremic symptoms present when glomerular filtration rate lower than 60 $\mathrm{ml} /$ minutes $/ 1.73 \mathrm{~m}^{2}$ surface body area (Meyer et al. 2007). This condition increases inflammation process and angiotensin II (Ang II) level results in heart failure (Smith et al. 2009; Meyer et al. 2007; Smith 2009).

Ang II activates NADPH oxidase in cardiac myocyte, therefore, results in increased reactive oxigen species (ROS) (Smith 2009). ROS induce apoptosis and necrosis which results in the release of ferrous by the cell in order to catalyze prooxidant reaction (Smith 2009; Larsen et al. 2012). Increase malondialdehyde (MDA) indicates an increase of oxidative stress in CKD (Larsen et al. 2012).

Inhibition of renin-angiotensin-aldosteron system (RAAS) is effective in reducing mortality and morbidity in cardiovascular diseases, but it could not stop its progression (Hoogwerf et al. 2010; Renke et al. 2008). Therefore, research in finding new drugs for CKD is in great demand (Small et al. 2012).

Targeting antioxidant system in CKD therapy is potential to be developed (Small et al. 2012). Quercetin, a flavonoid compound which is abundant in medicinal plants, possesses antioxidant activity and cardioprotective effect. It induces glutathione peroxidase (GPX), reduces MDA level, blocks RAAS, reduces brain natriuretic peptide (BNP) and minimizes myocardial fibrosis in cardiotoxic-induced cardiac fibrosis in the rats and rats model of hypertension (Bas et al. 2011; Li et al. 2013; Yan et al. 2013). However, its effect on uremic cardiomyopathy induced in rats by $5 / 6$ nephrectomy has not been investigated yet. Therefore, current study aims to determine cardioprotective effect of quercetin through antioxidant mechanism in rat model of CKD induced by 5/6 nephrectomy.

\section{METHODS}

\section{Animals}

Animal model used in this study was adapted from Soetikno et al. (2013) with modification. Male SpragueDawley rats with an average body weight of 150-300 g (BPOM RI) were used in this study. The experimental protocol was approved by the Ethical Committee of the University of Indonesia. Animals were housed in a controlled room and fed a standard laboratory diet and water ad libitum. The animals were randomly divided into four groups with six animals in each group. One group served as control and three groups underwent $5 / 6$ nephrectomy by surgical resection of the upperand lower-thirds of the left kidney, followed by a right nephrectomy 7 days later. The procedures were carried out under general anesthesia (ketalar $50 \mathrm{mg} / \mathrm{kg}$ i.p.). In the first week after the second surgery, the animals were randomly divided into quercetin treatment $(S N X+Q)$, captopril treatment (SNX+Cap), and untreated (SNX) groups. The $S N X+Q$ group was subjected to gavage with $100 \mathrm{mg} / \mathrm{kg}$ quercetin in $0.5 \%$ CMCNa daily (Wang et al. 2012). Quercetin were purchased from Sigma Aldrich (Sigma Aldrich, China). The SNX+Cap group received $10 \mathrm{mg} / \mathrm{kg}$ oral captopril in $0.5 \%$ CMCNa daily (Khattab et al. 2005). The SNX group and control group received aquadest. The animals were orally administered with distinctive substances for 8 weeks. After 11 weeks of treatment all rats were sacrificed, and the blood and heart tissues were collected for further analysis.

\section{Morphological Analysis}

Heart tissues were fixed in phosphate-buffered $10 \%$ (vol/vol) formaldehyde, $\mathrm{pH} \mathrm{7.2,} \mathrm{and} \mathrm{embedded} \mathrm{in}$ paraffin. Sections $(5 \mu \mathrm{m})$ were stained with Masson's trichrome. One microscopic field per section was analyzed by using a Optilab light microscope (Optilab), with the observer blind to the study group. Histological lesions (fibrosis) labeling was evaluated as follows: absent, 0 ; mild, 1; moderate, 2; severe, 3; and very severe, 4 .

\section{Measurement of Nitrogen Terminal fragment pro- Brain Natriuretic Peptide (NT-proBNP) content}

Blood samples were collected in Lithium Heparin vacutainer tubes. Litium Heparin blood was centrifuge at $3000 \times \mathrm{rpm}$ for $10 \mathrm{~min}$ at $4^{\circ} \mathrm{C}$ for separation of plasma. The collected plasma was utilized for the determination of NT-proBNP in accordance with the

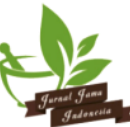


NT-proBNP ELISA kit instructions (Elabscience). The optical density is measured spectrophotometrically at $450 \mathrm{~nm}$ (Xmark microplate spectrophotometer, Biorad).

\section{Measurement of malondialdehyde (MDA) content}

Blood samples were collected in Lithium Heparin vacutainer tubes. Lithium Heparin blood was centrifuge at $3000 \times \mathrm{rpm}$ for $10 \mathrm{~min}$ at $4^{\circ} \mathrm{C}$ for separation of plasma. The collected plasma was utilized for the determination of MDA using TBARS method with 1,1,3,3-tetrametoksipropan 99 (TMEP) (Aldrich 108383 ) as the standard. The optical density is measured spectrophotometrically at $530 \mathrm{~nm}$ (UV/VIS Spectrophotometer, Perkin Elmer) (Layal 2015).

Meanwhile, heart tissues were rinsed, weighed,

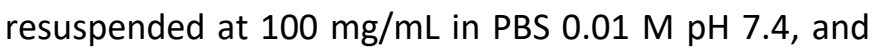
homogenized. After centrifugation at $3000 \mathrm{rpm}$ for 10 $\min$ at $4^{\circ} \mathrm{C}$, the supernatants were collected and utilized for the determination of MDA using TBARS method with 1,1,3,3-tetrametoksipropan 99 (TMEP) (Aldrich 10838-3) as the standard. The optical density is measured spectrophotometrically at $530 \mathrm{~nm}$ (UV/VIS Spectrophotometer, Perkin Elmer) (Layal 2015).

\section{Measurement of glutathione peroxidase (GPX) activity}

Heart tissues were rinsed, weighed, resuspended at $100 \mathrm{mg} / \mathrm{mL}$ in PBS $0.1 \mathrm{M} \mathrm{pH} 7.4$ (contains $0.1 \%$ protease inhibitor), and homogenized. After centrifugation at $3000 \mathrm{rpm}$ for $10 \mathrm{~min}$ at $4^{\circ} \mathrm{C}$, the supernatants were collected and utilized for the determination of GPX activity in accordance with the GPx assay kit instructions (Ransel, Randox) with modification. GPX activity on heart tissues was measured using an ultraviolet-visible spectrophotometer (Perkin Elmer). The oxidation of nicotinamide adenine dinucleotide phosphate reduced (NADPH) to nicotinamide adenine dinucleotide phosphate was measured by the decrease in absorbance at $340 \mathrm{~nm}$.

\section{Statistical analysis}

Numeric data were expressed as mean \pm SD while ordinal data as median and range. Data were analyzed using one-way analysis of variance (ANOVA) followed by Multiple LSD or Kruskal Wallis followed by Mann Whitney when appropriate.

\section{RESULTS AND DISCUSSION}

Light microscopy analysis showed that all the nephrectomized rats had developed a sign of mild myocardial fibrosis (Figure 1) where no effects were found in quercetin and captopril groups $(p>0.05)$ (Table $1)$.

Meanwhile, NT-proBNP level remained unchanged even though myocardial fibrosis was observed in all the nephrectomized groups ( $p>0.05)$. In this condition, quercetin and captopril administration had no effect on NT-proBNP level ( $p>0.05$ ) (Figure 2).

TBARS contents were determined to evaluate lipid oxidation. In the SNX group, cardiac TBARS contents were the highest among other groups $(p>0.05)$. It appears that the administration of quercetin and captopril reduce the cardiac TBARS content $(p>0.05)$ (Figure 3). On the other hand, plasma TBARS content tended to decrease after nephrectomy (Figure 4).

An obvious change was observed on cardiac GPX activity. All groups of nephroctomized rats had significant increase of GPX activity $(p<0.05)$ where no effects were found in quercetin and captopril groups ( $p>0.05$ ) (Figure 5).

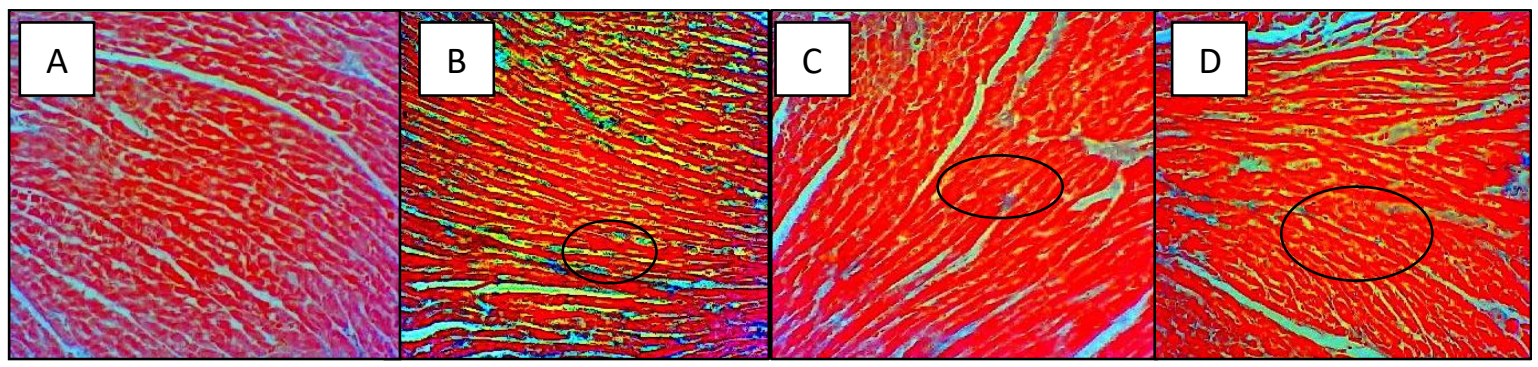

Figure 1. Effect of quercetin and captopril treatment on myocardial fibrosis in 5/6-nephrectomized rat. (A) Normal; (B) SNX, collagen is seen; (C) $S N X+Q$, collagen is seen; (D) $S N X+C a p$, collagen is seen. Massons' Trichrome stain; magnification, $x 100$. SNX=5/6 nephrectomy, $Q=$ quersetin $100 \mathrm{mg}$, Cap= 


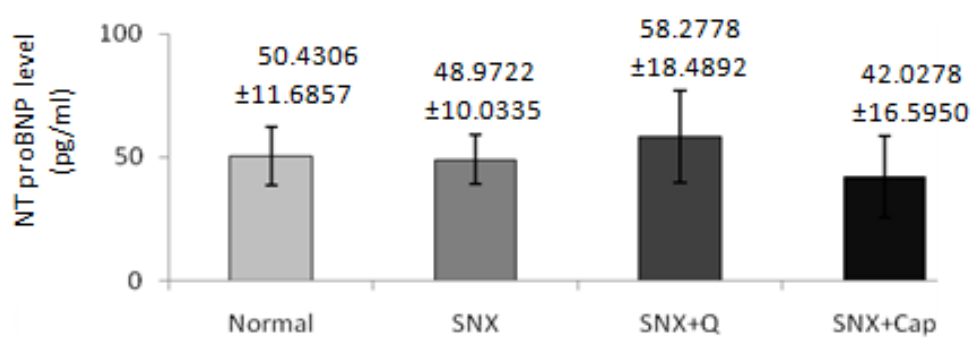

Figure 2. Effect of quercetin and captopril treatment on NT-proBNP level in 5/6-nephrectomized rat. SNX=5/6 nephrectomy, $\mathrm{Q}=$ quersetin $100 \mathrm{mg}$, Cap= captopril $10 \mathrm{mg}$. Data are expressed as mean $\pm \mathrm{SD}$.

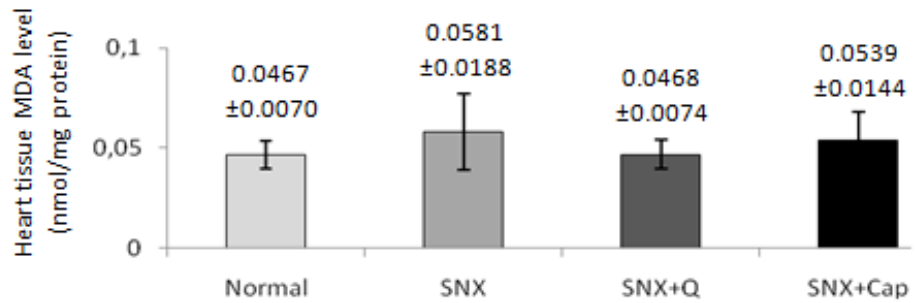

Figure 3. Effect of quercetin and captopril treatment on cardiac MDA level in 5/6-nephrectomized rat. SNX=5/6 nephrectomy, $\mathrm{Q}=$ quersetin $100 \mathrm{mg}$, Cap= captopril $10 \mathrm{mg}$. Data are expressed as mean \pm SD.

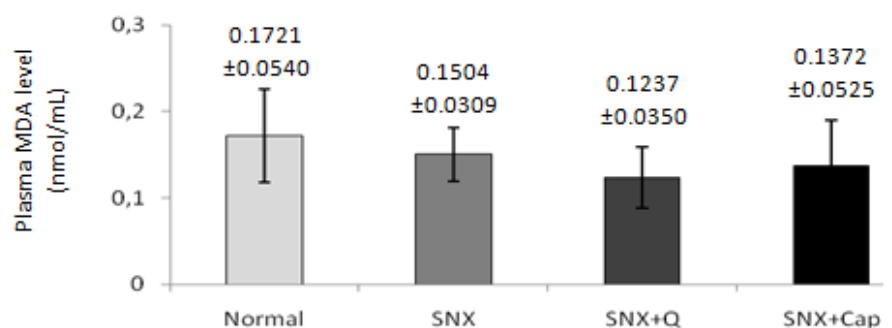

Figure 4. Effect of quercetin and captopril treatment on plasma MDA level in 5/6-nephrectomized rat. SNX=5/6 nephrectomy, $\mathrm{Q}=$ quersetin $100 \mathrm{mg}$, Cap= captopril $10 \mathrm{mg}$. Data are expressed as mean $\pm \mathrm{SD}$.

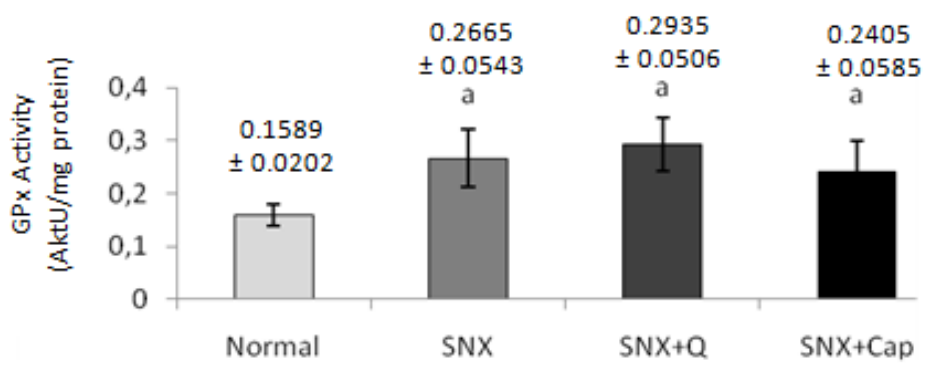

Figure 5. Effect of quercetin and captopril treatment on cardiac GPX activity in 5/6-nephrectomized rat. $\mathrm{SNX}=5 / 6$ nephrectomy, $\mathrm{Q}=$ quersetin $100 \mathrm{mg}$, Cap= captopril $10 \mathrm{mg}$. Data are expressed as mean $\pm \mathrm{SD}$. a,$p<0.05$.

\section{Discussions}

$5 / 6$ nephrectomy (SNX) in rat is a gold standard to study CKD. The pathophysiological characteristics produced by this method are similar to CKD in human such as glomerular hypertrophy, proteinuria, and glomerular injury (Chaykovska et al. 2011; Griffin et al.
1994). Stabile and moderate renal failure were achieved through hemodynamic changes and disturbances in renal autoregulation (Griffin et al. 1994; Tyralla et al. 2011).

Numerous changes were observed in cardiac tissue in CKD. These includes decrease myocardial capillary 
density, decrease aortic lumen diameter, increase aortic media thickness, and upregulation of myocardial angiotensin II type I receptor, renin, profibrotic cytokines, and brain natriuretic peptide (BNP) (Chaykovska et al. 2011; Tyralla et al. 2011; Kennedy et al. 2008).

Total number of animals used were 24 and survival rate after SNX surgery was 57\%. Layal (2015) reported that nephrectomy significantly increased proteinuria $(p<0.05)$ and plasma urea level $(p<0.05)$. From this study, neither quercetin nor captopril had effect on plasma urea concentration $(p>0.05)$. However, captopril significantly reduced proteinuria $(p<0.05)$ but not quercetin $(p>0.05)$. Meanwhile, there was no significant difference among all of the groups in average body weight, heart weight, and heart-to-body weight ratio (data not shown).

Captopril was used as a standard therapy because of its ability to reduce proteinuria in CKD patients (Tyralla et al. 2011; Viberti et al. 1994). Captopril with dose of $10 \mathrm{mg}$ was chosen because it reduces creatinine, blood pressure, and myocardial hypertrophy in animal model of hypertension (Khattab et al. 2005). Meanwhile, we used $100 \mathrm{mg}$ dose of quercetin because it reduced proteinuria in streptozotocin induced-diabetes rat (Wang et al. 2012).

In this study, 5/6 nephrectomy resulted in mild myocardial fibrosis as shown by mild collagen deposition between myocardium in line with Smith (2009). Quercetin and captopril, each, insignificantly reduced it $(p>0.05)$. However, Tyralla et al. (2011) reported that enalapril, an angiotensin converting enzyme (ACE) inhibitor, significantly reduced myocardial fibrosis in 5/6-nephrectomized rat and Yan et al. (2014) reported that quercetin reduced myocardial fibrosis in rat with unilateral ureteral obstruction.

$\mathrm{N}$-terminal fragment pro-brain natriuretic peptide (NT-proBNP) is a cardiac marker used in the skrinning of ventricular diastolic dysfunction in CKD patient (Chaykovska et al. 2011; Adamcova et al. 2013; Nunes et al. 2013). It is released by myocyte to blood vessel, as a response to mechanical stress (ventricular overload) in order to reduce preload and afterload (Larsen et al. 2010).

In this study, 5/6 nephrectomy did not change NTproBNP level $(p>0.05)$, neither did quercetin and captopril administration $(p>0.05)$. Preserved NTproBNP in this study might be as a result of preserved renin-angiotensin-aldosteron activity due to reduced number of juxtaglomerular cells which resulted in no ventricular overload (Adamcova et al. 2013; Singh et al. 2010; Eraranta et al. 2014; Kujal et al. 2008). On the contrary, Chaykovska et al. (2011) reported that 5/6 nephrectomy increased BNP level. As a result, neither quercetin nor captopril reduced the BNP level. This is in contrast to Yan et al. (2014) who reported BNP reducing effect of quercetin in rat with unilateral ureteral obstruction. Similar with this, Falcao et al. (2004) also reported BNP reducing effect of captopril in dilated ventriular hypertensive patient.

Malondialdehyde (MDA) is a final product of lipid peroxidation that represents cell destruction (Xu et al. 2014). Oxidized phospholipid involves in activation of inflammatory and apoptosis pathways (Deignera et al. 2008). In this study, MDA was measured using TBARS reaction and revealed that nephrectomy affect neither heart nor plasma MDA levels ( $p>0.05$ ). Romero et al. (1999) reported that urinary MDA level dropped back to normal value in 8 weeks after nephrectomy. Urinary MDA represented plasma MDA in CKD patient as reported by Chang et al. (2005).

Meanwhile, Bas et al. (2011) reported that quercetin reduced cardiac MDA in cardiotoxic-induced rat. Insignificant decrease in cardiac MDA ( $p>0.05)$ after quercetin administration was caused by insignificant increase of cardiac MDA after nephrectomy.

On the other hand, insignificant increase of cardiac MDA by captopril administration ( $p>0.05$ ) could be caused by upregulation of $A C E$ as a result of its chronic inhibition which result in increase of NADPH oxidase activation by Ang II (Costerousse et al. 1998).

Meanwhile, quercetin and captopril insignificantly reduced plasma MDA level ( $p>0.05)$. This is in line with Deng et al. (2001) and Duarte et al. (2002). Deng et al. (2001) reported that captopril reduced plasma MDA level in 5/6-nephrectomized rats while Duarte et al. (2002) reported that quercetin reduced plasma MDA in rat model of hypertension. This insignificance could be caused by insignificant decrease of plasma MDA after nephrectomy.

Quercetin mechanism on reducing lipid peroxidation includes xanthine oxidase inhibition, metal chellation, radical hydroxy scavenging, and upregulation of endogenous antioxidant enzyme (Yan et al. 2014). Meanwhile, captopril reduces oxidative stress through the decrease of Ang II that plays important roles in activating NADPH oxidase (Sayed et al. 2008). 
Glutathione peroxidase plays more important role in antioxidant mechanism than catalase, superoxide dismutase, glutathioe S-transferase, and glutathione reductase in coronary artery disease patient (Blankenberg et al. 2003; Ho et al. 1998; Lapenna et al. 1998). Some study revealed GPX activity as potential diagnostic and prognostic marker in CKD patient (Blankenberg et al. 2003). Depletion of its activities was caused by uremia, an increase in lipid peroxidation, a decrease in functional renal mass, and a biochemical inactivation (Krofic et al. 2014).

This study revealed that 5/6 nephrectomy significantly increased cardiac GPX activity $(p<0.05)$. Similar with this, Lim et al. (2004) found that cardiac GPX was also upregulated through $5 / 6$ nephrectomy in the same animal model. Preserved endogenous antioxidant defense mechanism in the compensatory phase, indicating that cardiac adaptation mechanism had not deteriorated yet in uremic milieu.

Significant increase of cardiac GPX activity after 5/6 nephrectomy resulted in insignificant increase of its activity after quercetin administration ( $p>0.05)$ even though Bas et al. (2011) reported a significant increase in it.

Meanwhile, insignificant decrease in cardiac GPX activity after captopril administration $(p>0.05)$ was in line with Shouman et al. (2006) that revealed decrease in GPX activity in cardiotoxic-induced rat. These insignificant activities could also caused by significant increase of GPX activity after 5/6 nephrectomy.

Based on these data, quercetin did not ameliorate myocardial fibrosis and had no effect on cardiac marker in uremic rat heart induced by $5 / 6$ nephrectomy. Apparently, mild myocardial fibrosis in the uremic milieu gives preserved cardiac function. No noticeable changes were present on the cardiac endogenous antioxidant defense mechanism after quercetin administration.

However, this study still had many limitations. The author suggests that in the next study, natrium supplementation should be given to the rat because of its sensitivity to natrium hypertension (Ylitalo et al. 1976) and a longer study until 3-6 months or until cardiovascular morbidity and mortality were observed (Griffin et al. 1994). Meanwhile, testing compound could be administered after a positive sign of cardiac disease. Additional parameters such as blood pressure monitoring and echocardiography observations are also suggested.

\section{CONCLUSION}

Based Uremic rats' heart induced by $5 / 6$ nephrectomy demonstrated mild myocardial fibrosis but preservation of cardiac function as shown by insignificant changes in plasma NT-proBNP. Significant increased in GPX activity in uremic rats' heart compared to normal control suggests induction of antioxidant defense mechanisms that might not be exhausted yet. This condition highlighted a compensatory phase which was unchanged following chronic either quercetin or captopril administration. Insignificant changes in plasma and cardiac MDA levels in uremic rats' heart compared to normal control also support this finding.

\section{ACKNOWLEDGMENT}

The authors thank Nina Artanti, PhD for her support and collaboration.

\section{REFERENCES}

Adamcova M, Ruzickova S, Simko F. 2013. Multiplex immunoassays for simultaneous quantification of cardiovascular biomarkers in the model of L-NAME hypertensive rat. Journal of Physiology and Pharmacology. 64 (2): 211-17.

Bas H, Yusuf K. 2011. Chlorpyrifos induced cardiotoxicity in rats and the protective role of quercetin and catechin. Gazi University Journal of Science. 24(3):387-95.

Blankenberg S, Rupprecht HJ, Bickel C, Torzewski M, Hafner G, Tiret L, et al. 2003. Glutathione peroxidase 1 activity and cardiovascular events in patients with coronary artery disease. The New England Journal of Medicine. 349:1605-13.

Chang JM, Kuo MC, Kuo HT, Chiu YW, Chen HC. 2005. Increased glomerular and extracellular malondialdehyde levels in patients and rats with diabetic nephropathy. The Journal of laboratory and clinical medicine. 146(4):210-5.

Chaykovska L, von Websky K, Rahnenfuhrer J, Alter M, Heiden S, Fuchs $\mathrm{H}$, et al. 2011. Effects of DPP-4 inhibitors on the heart in a rat model of uremic cardiomyopathy. PLOS ONE. 6(11):1-9.

Codognotto M, Piccoli A, Zaninotto M, Mion M, Plebani $M$, Vertolli $U$, et al. 2007. Renal dysfunction is a confounder for plasma natriuretic peptides in detecting heart dysfunction in uremic and idiopathic dilated cardiomyopathies. Clinical Chemistry. 53(12):2097-104 
Costerousse $\mathrm{O}$ et al. 1998. Angiotensin I-converting enzyme inhibition but not angiotensin II suppression alters angiotensin I-converting enzyme gene expression in vessels and epithelia. The Journal of pharmacology and experimental therapeutics. 284: 1180-7.

Deignera HP, Hermetter A. 2008. Oxidized phospholipids: emerging lipid mediators in pathophysiology. Current Opinion in Lipidology. 19:289-94.

Deng G, Vaziri ND, Jabbari B, Ni Z, Yan XX. 2001. Increased tyrosine nitration of the brain in chronic renal insufficiency: reversal by antioxidant therapy and angiotensin-converting enzyme inhibition. The Journal of the American Society of Nephrology. 12: 1892-9.

Duarte J, Jimenez R, O'Valle FF, Galisteo M, PerezPalencia R, Vargas F, Perez-Vizcaino F, Zarzuelo A, Tamargo J. 2002. Protective effects of the flavonoid quercetin in chronic nitric oxide deficient rats. Journal of Hypertension. 20:1843-54.

Eraranta A. 2014. Hyperuricemia and calcium phosphate metabolisme in experimental renal insuficiency: Effects on oxidative stress and renin angiotensin aldosteron system [Dissertation]. Helsinki (FI): School of Medicine, University of Tampere.

Falcao LM, Pinto F, Ravara L, van Zwieten PA. 2004. BNP and ANP as diagnostic and predictive markers in heart failure with left ventricular systolic dysfunction. Journal of the Renin-AngiotensinAldosterone System. 5(3):121-9.

Glassock RJ, Pecoits-Filho R, Barberato SH. 2009. Left Ventricular Mass in Chronic Kidney Disease and ESRD. Clinical Journal of the American Society of Nephrology. 4:S79-91

Griffin KA, Picken M, Bidani AK. 1994. Method of renal mass reduction is a critical modulator of subsequent hypertension and glomerular injury. 1994. Journal of the American Society of Nephrology. 4: 2023-31.

Ho Y, Magnenat JL, Gargano M, Cao J. 1998. The nature of antioxidant defense mechanisms: A lesson from transgenic studies. Environmental Health Perspectives. 106 (Suppl 5): 1219-28.

Hoogwerf BJ. 2010. Renin-angiotensin system blockade and cardiovascular and renal protection. The American Journal of Cardiology. 105(1 Suppl):30A$5 \mathrm{~A}$.
Jha V, Garcia-Garcia G, Iseki K, Li Z, Naicker S, Plattner B, et al. 2013. Chronic kidney disease: Global dimension and perspectives. The Lancet. 382(9888):260-72.

[Balitbang Kemenkes RI] Kementrian Kesehatan RI, Badan Penelitian dan Pengembangan. 2013. Riset kesehatan dasar: riskesdas 2013. Jakarta (ID): Kementrian Kesehatan RI.

Kennedy DJ, Elkareh J, Shidyak A, Shapiro AP, Smaili S, Mutgi K, et al. 2008. Partial nephrectomy as a model for uremic cardiomyopathy in the mouse. American Journal of Physiology-Renal Physiology. 294: F450-4.

Khattab MM, Mostafa A, Al-Shabanah O. 2005. Effects of captopril on cardiac and renal damage, and metabolic alterations in the nitric oxide-deficient hypertensive rat. Kidney and Blood Pressure Research. 28(4):243-50.

Krofic M, Tozon N, Svete AN. 2014. Plasma and erythrocyte glutathione peroxidase activity, serum selenium concentration, and plasma total antioxidant capacity in cats with IRIS stages I-IV chronic kidney disease. Journal of Veterinary Internal Medicine. 28:130-6.

Kujal P, Vernerová Z. 2008. 5/6 nephrectomy as an experimental model of chronic renal failure and adaptation to reduced nephron number. Ceskoslovenska Fysiologie. 57(4):104-9.

Laecke SV, Biesen WV, Vanholder R. 2015. The paradox of bardoxolone methyl: A call for every witness on the stand? Diabetes, Obesity and Metabolism. 17: 9-14.

Lapenna D, de Gioia S, Ciofani G, Mezzetti A, Ucchino S, Calafiore AM, et al. 1998. Glutathione-related antioxidant defenses in human atherosclerotic plaques. Circulation Journal. 97:1930-34.

Larsen T, Narala K, McCullough PA. 2012. Type 4 cardiorenal syndrome: Myocardial dysfunction, fibrosis, and heart failure in patients with chronic kidney disease. Journal of Clinical and Experimental Cardiology. 3(4):1-13.

Layal K. 2015. Efek kuersetin terhadap ginjal tikus model penyakit ginjal kronik melalui jalur NRF2 [thesis]. Jakarta (ID): Fakultas Kedokteran, Universitas Indonesia.

Li M, Jiang Y, Jing W, Sun B, Miao C, Ren L. 2013. Quercetin provides greater cardioprotective effect than its glycoside derivative rutin on isoproterenol-

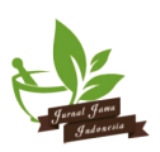


induced cardiac fibrosis in the rat. Canadian Journal of Physiology and Pharmacology. 91(11):951-9.

Lim CS, Vaziri ND. 2004. The effects of iron dextran on the oxidative stress in cardiovascular tissues of rats with chronic renal failure. Kidney International. 65(5):1802-9.

Lopez B, González A, Hermida N, Laviades C, Díez J. 2008. Myocardial fibrosis in chronic kidney disease: Potential benefits of torasemide. Kidney International Supplements . 111 :S19-23.

Meyer TW, Hostetter TH. 2007. Uremia. The New England Journal of Medicine. 357(13):1316-25.

Nunes S, Soares E, Fernandes J, Viana S, Carvalho E, Pereira FC, Reis F. 2013. Early cardiac changes in a rat model of prediabetes: brain natriuretic peptide overexpression seems to be the best marker. Cardiovascular Diabetology. 12 (44):1-11.

Renke $\quad M$, Tylicki L, Rutkowski P, Larczyński W, Aleksandrowicz E, Lysiak-Szydłowska W, et al. 2008. The effect of $\mathrm{N}$-acetylcysteine on proteinuria and markers of tubular injury in non-diabetic patients with chronic kidney disease. A placebocontrolled, randomized, open, cross-over study. Kidney and Blood Pressure Research. 31(6):404-10.

Romero F, Rodrigues-Iturbe B, Chaykovska L, von Websky K, Rahnen J, Alter M, et al. 1999. Mycophenolate mofetil prevents the progressive renal failure induced by $5 / 6$ renal ablation in rats. Kidney International. 55:945-55.

Sayed ESE, Abd-Ellah MF, Attia SM. 2008. Protective effect of captopril against cisplatin-induced nephrotoxicity in rats. Pakistan Journal of Pharmaceutical Sciences. 21(3): 255-61.

Shouman SA, Noimi FM, Gashlan HM. 2006. Evaluation of the potential protective effect of captopril against doxorubicin-induced cardiotoxicity in rats. Journal of the Egyptian Society of Toxicology. 35: 123-9.

Singh V, Martinezclark P, Pascual M, Shaw ES, O'Neill WW. 2010. Cardiac biomarkers - the old and the new: A review. Coronary Artery Disease. 21:24456.

Small DM, Coombes JS, Bennett N, Johnson DW, Gobe GC. 2012. Oxidative stress, anti-oxidant therapies and chronic kidney disease. Nephrology. 17: 31121.

Smith K, Semple D, Bhandari S, Seymour AL. 2009. Cellular basis of uraemic cardiomyopathy: A role for erythropoietin. European Journal of Heart Failure. 11: 732-8.

Smith K. 2009. The Impact of Erythropoietin on Uraemic Cardiomyopathy [PhD thesis]. Kingston upon Hull (GB): University of Hull.

Soetikno V, Sari FR, Veeraveedu PT, Thandavarayan RA, Harima M, Sukumaran V, et al. 2011. Curcumin ameliorates macrophage infiltration by inhibiting NF-kappaB activation and proinflammatory cytokines in streptozotocin induced-diabetic nephropathy. Nutrition \& Metabolism. 8(1):164959.

Sviglerov J, Kuncov J, Nalos L, Tonar Z, Rajdl D, Stengl M. 2010. Cardiovascular parameters in rat model of chronic renal failure induced by subtotal nephrectomy. Physiological Research. 59 (Suppl. 1): S81-S88.

Tyralla K, Adamczak M, Benz K, Campean V, Gross M-L, Hilgers K, et al. 2011. High-dose enalapril treatment reverses myocardial fibrosis in experimental uremic cardiomyopathy. PLOS ONE. 6(1):1-11.

Viberti G, Mogensen CE, Groop LC, Pauls JF. 1994. Effect of captopril on progression to clinical proteinuria in patients with insulin-dependent diabetes mellitus and microalbuminuria. European Microalbuminuria Captopril Study Group. The Journal of the American Medical Association. 271(4):275-9.

Wang C, Pan Y, Zhang QY, Wang FM, Kong LD. 2012. Quercetin and allopurinol ameliorate kidney injury in STZ-treated rats with regulation of renal NLRP3 inflammasome activation and lipid accumulation. PLOS ONE. 7(6): 1-14.

Xie J, Yoon J, An S, Kuro-o M, Huang C. 2015. Soluble klotho protects against uremic cardiomyopathy independently of fibroblast growth factor 23 and phosphate. Journal of the American Society of Nephrology. 26(5):1150-60.

Xu Y, Yang Y, Luo YQ. 2014. Effect of atorvastatin on serum oxidative stress and $\mathrm{N}$-terminal brain natriuretic peptide expression in rats. Asian Pacific Journal of Tropical Medicine. 7(5):398-401

Yan L, Zhang JD, Wang B, Li YJ, Jiang H. 2013. Quercetin inhibits left ventricular hypertrophy in spontaneously hypertensive rats and inhibits angiotensin II-induced $\mathrm{H} 9 \mathrm{C} 2$ cells hypertrophy by enhancing PPAR-c expression and suppressing AP-1 Activity. PLOS ONE. 8(9): 1-14. 
Yan Y, Feng Y, Li W, Che JP, Wang GC, Liu M, et al. 2014. Protective effects of quercetin and hyperoside on renal fibrosis in rats with unilateral ureteral obstruction. Experimental and Therapeutic Medicine. 8: 727-30.
Ylitalo P, Hepp R, Möhring J, Gross F. 1976. Effects of varying sodium intake on blood pressure and reninangiotensin system in subtotally nephrectomized rats. Journal of Laboratory and Clinical Medicine. 88(5):807-16. 